\title{
Research on the Development path of Exhibition venues Informatization
}

\author{
Di Jiayu ${ }^{1, \text { a }}$, Guo Haixia ${ }^{2, \text { b }}$ \\ ${ }^{1}$ School of Management, Harbin University of Commerce, Harbin, China \\ ${ }^{2}$ School of Management, Harbin University of Commerce, Harbin, China \\ a844183094@qq.com \\ bhaixia07@163.com
}

Keywords: Exhibition venues, “Internet+", Development path

\begin{abstract}
With the rapid development of new technology and equipment, the traditional management mode of exhibition venues in China needs to be changed. The establishment of online venue platform, intelligent pavilion system and central wireless network terminal, the operation of the virtual exhibition, the invention of exhibition hall service robot and other measures need to be developed. And through the above development path, to solve the extant problems of exhibition venues, to achieve efficient and reasonable development of exhibition venues.
\end{abstract}

\section{Introduction}

Under the background of the Internet era, the traditional management mode of exhibition venues in China has been severely impacted. The low utilization rate of the venues and the shortage of talents are gradually emerging. At the same time, the emergence of new technology and new equipment brings new ideas to the management of the venue. The traditional model is in urgent need of change, and the future development path of the exhibition venue should be put forward from the perspective of Internet.

\section{Research results}

Wu Xiaofang pointed out that there are problems in the management of exhibition venues in China, such as the increase in quantity and imbalance in structure, the coexistence of total shortage and surplus, etc. And Wu also points out that the way of exhibition venues' development needs to be innovated [1], and Wang Dongmei points out that if we fail to solve the problem of the follow-up service of the venues after the large-scale exhibition activities, it will result in a huge waste of resources and the economic and social value of the exhibition activities will also be reduced. Therefore, we should make a good use of it and maximize the role of the exhibition venues [2]. Zhao Guangzhou pointed out that at present, many large exhibition venues in our country still have problems such as mass upfront investment, unreasonable layout, single function, low utilization ratio of venues and so on. For this reason, it is suggested to speed up the market-oriented operation transformation of the exhibition venues, run exhibitions in various forms. We should actively deal with market competition and open up diversified management mode so as to make rational use of large exhibition venues [3].

Zhang Ronglin noted that in the Internet era, exhibition venues have begun to combine intellectual products, high technology with innovative services, create their own "intelligent venue" brand, and cooperate with the surrounding industries to carry out multi-dimensional marketing and promotion. And then for the venue to bring more social and economic benefits, forming a complete industrial chain [4]. Li Renqing mentioned how the traditional exhibition industry can make full use of the mobile Internet and bring into play the superposition effect combined with big data, which is an important direction for the development of the Wisdom venues [5]. 


\section{Existing problems}

\subsection{Low utilization rate of the venues.}

According to the statistics of the China Exhibition Economic Development report 2017 released by the China Council for the Promotion of International Trade, most of the exhibition venues in China are mainly devoted to exhibition business, and the number of exhibition venues is increasing year by year. However, the overall utilization rate of the exhibition hall is low, and the project repetition rate is high, which is not conducive to the efficient development of the venues.

Table 1 Distribution of national pavilions in 2017

\begin{tabular}{cccc}
\hline $\begin{array}{c}\text { The number } \\
\text { of exhibitions held }\end{array}$ & $\begin{array}{c}\text { The number of } \\
\text { venues }\end{array}$ & $\begin{array}{c}\text { Proportion of } \\
\text { total national } \\
\text { pavilions }\end{array}$ & $\begin{array}{c}\text { Changes in } \\
\text { quantities with 2016 }\end{array}$ \\
\hline More than $\mathbf{4 0}$ & 18 & $12 \%$ & 1 \\
$\mathbf{3 0 - 4 0}$ & 11 & $7 \%$ & 3 \\
$\mathbf{2 0 - 3 0}$ & 13 & $8 \%$ & -10 \\
$\mathbf{1 0 - 2 0}$ & 31 & $20 \%$ & 6 \\
\hline Less than 10 & 79 & $52 \%$ & 17 \\
\hline
\end{tabular}

As shown in Table 1, the number of venues at all stages is increasing, except for those with 20-30 exhibitions held annually. In 2017, there are 3663 exhibitions were held totally, of which 40 or more accounted for $34 \%$ of the total, while $52 \%$ of the total number of venues held less than $20 \%$ of the total number of national exhibitions. The data clearly show that there are great differences in the number of exhibitions run by exhibition halls in China, and the utilization ratio is not balanced.

\subsection{Business philosophy does not fit in with the trend of younger audience.}

The current market consumption of the mainstream target population to young development, more after 80, 90 generation of young people. However, the large exhibition site area and the traffic jam which made by the exhibition will take a long time to visit the exhibition. These characteristics will restrict the young audience from participating in the exhibition. And, along with the technological progress, they also more and more favor the Internet and the network, and has the higher pursue to the service experience. On the basis of maintaining the traditional business mode, it also requires the venues' manager to change its ideas in service and operation.

\subsection{Lack of professional management talents in exhibition venues.}

With the strong development of exhibition economy in our country, the demand for high-quality exhibition talents is expanding rapidly in the industry, and the specialization of venue management and operation also requires the professional management staffs. At present, in our country, many employees of exhibition venues are unprofessional. They not only lack professional knowledge of exhibition, but also do not have a clear understanding of the management of exhibition venues, including the safety management of venues, the management of the environment and the temperature management, etc. And the exhibition venue management lacks the definite rules and regulations for the management staff reference, including standard indoor temperature and humidity, passenger flow analysis and so on. In the Internet era, the management of exhibition venues is in urgent need of new technology and equipment to standardize.

\subsection{Weak service consciousness of venue staff.}

At present, the on-site service staffs of exhibition venues in our country are mostly part-time college students, or not fixed staffs, which may affect the professional nature of the exhibition. Site service staffs play a very important role in the operation of the entire exhibition. The arrangement of site personnel will affect the efficiency of admission, registration, check-in and other links. The management and control of the exhibition site will affect the order of the entire exhibition site. 
Moreover, the selection of service personnel will lack standards and considerations. It is also difficult to understand the strength of its service consciousness. Exhibition venues should solve this problem to ensure that the fair is more safe and smooth operation.

\subsection{Low availability of on-site communication network for exhibition venues.}

The basic network architecture of wireless local area network, sensor network and mobile communication network is now the necessary infrastructure in the exhibition venues. However, at present, a large number of venues communication networks have low availability, wireless network coverage is small. And during the exhibition period, most of the venues are in the condition of no signal and no network, only a few venues have more complete network coverage. Information is one of the most important exhibition products, exhibition as an information exchange platform, without the network and communication as a carrier, is not conducive to the exchange of information dissemination; trade is not conducive to the conduct of transaction [7].

\section{Information development path}

\subsection{Establishment of online venue Information platform.}

Establish and improve the customer data center to assist the exhibitors in the exhibition. The necessary information technology and means are used to store the information of exhibitors and professional visitors in a classified manner. When the exhibition items are determined, the exhibitors can be assisted to recruit and improve their efficiency. At the same time, the online registration entrance of the platform is also open, the passenger flow of each day can be estimated; the information of the exhibition venues will be published so as to facilitate the selection and determination of exhibitors. On the one hand, it is convenient for the group exhibitors to select the free time of the venue and to avoid holding many similar theme exhibitions in a short period of time, so as to reduce the repetition rate of the exhibitions. On the other hand, it is convenient for exhibitors to choose exhibition and booth on the Internet, and to provide one-stop service for exhibitors. The online venue platform is not only the integration of information, but also more conducive to reuse. The exhibition hall itself can organize its own exhibition during the low peak period, through the evaluation and analysis of the previous exhibition; select the most appropriate project to improve the success rate.

\subsection{Online virtual exhibition running at the same time.}

Online virtual exhibition is a form of digital exhibition, using digital technology, VR/AR technology, and large data technology, the entity exhibition 1:1 running at the same time is restored to the Internet to form a virtual exhibition. The virtual exhibition on line is an effective measure to solve target audience becoming younger. It can satisfy the characteristics of fast pace of life and favor the Internet. The informatization of the exhibition venues focuses more on the construction of the soft environment, which is more important than the hard environment of the domestic exhibition venue, achieve the exhibition venue differentiation and innovative management. In modern times, young people prefer the efficient lifestyle; the digital form venues can reappear the physical exhibition on the Internet, expand the target group, and attract more audience.

\subsection{Establishing the system of intelligent venue.}

The intelligent exhibition venue system is through the use of the Internet of things technology, since the exhibition venue is reasonable and effective management, to meet the timely processing of a large number of real-time information in the process of exhibition management, the comprehensive perception of the exhibition activities, the timely prediction or control of the development of crisis, early prevention and control of possible dangerous accidents and control. In the environment control, we can make the most suitable temperature and humidity, the most comfortable air quality, and carry out the overall management through the intelligent exhibition hall system. In the passenger flow, the intelligent exhibition hall system in real time statistics the number of participants, and statistics the peak time of the daily passenger flow, through the human 
heat map to count the most popular exhibition platform. In security, the intelligent Exhibition venue system can find the conflict events in time through the human body heat map.

\subsection{Inventing exhibition venue service robot.}

The venue service robot can replace the manual entrance guard, and the confirmed entrance can ensure the order of admission and improve the efficiency of admission. At the same time, it can directly count the number of exhibitors, so as to facilitate the later data processing and feedback evaluation. The venue service robot can also share the task of manual check-in. Exhibitors or professional visitors can choose according to their own preferences. Robots can provide a variety of languages to facilitate exhibitors and spectators from different countries. At the same time, working efficiency can be improved by using robots.

\subsection{Establishment of central wireless network and communication network terminal.}

In the existing exhibition venues, the network signal and communication network is unable to meet the intensive mobile demand, so the central wireless network and the communication network are the most effective way to realize the intelligent and networked road of exhibition venues. The establishment of a central wireless network and a communications network will ensure the interior of the venue, where everyone has a mobile phone network, which is the most important of the venues undefined infrastructure, whether today undefined $4 \mathrm{G}$ or wireless network. The exhibition is a high-speed information dissemination platform, whether between buyers and sellers of current transactions or subsequent transactions; whether between the general audience and exhibitors, or between major customers and exhibitors, the need for network and communication.

\section{Conclusion}

For the exhibition venues, reasonable and effective management has promoted the development of the venues. In the current Internet era, the managers of exhibition venues must change their perspective, use advanced management models and change management methods to ensure the order of the exhibition site, improve the utilization rate of exhibition halls, promote the development of exhibition venues and promote the development of the exhibition industry. At the same time to achieve the venues Internet transformation, close to the national strategy, healthy and stable development, to meet the greater challenges.

\section{References}

[1] Wu Xiaofang, in: Research on the present situation and Countermeasures of Exhibition and Exhibition venues in China (2009).

[2] Wang Dongmei, in: Reflections on the follow-up utilization of the exhibition venues left over from large-scale exhibition activities in China (2013).

[3] Yong Shu Li and Zhao Guangzhou, in: Problems and Countermeasures in the utilization of large exhibition venues in China (2016).

[4] Zhang Ronglin, in: The path Choice of "intellectual stadiums" under the background of "Internet" [D] Beijing: capital Institute of physical Education (2017).

[5] Li Renqing, in: New Mode of intellectual venues (2016)

[6] yuan Shuai, in: How to Information Construction and Development of Exhibition Hall under the New normal of "Internet Exhibition" (2017). 